\title{
Low expression of ryanodine receptor 2 is associated with poor prognosis in thyroid carcinoma
}

\author{
NIZHEN XU, DEGUANG ZHANG, JIAN CHEN, GAOFEI HE and LI GAO \\ Department of Head and Neck Surgery, Sir Run Run Shaw Hospital, School of Medicine, \\ Zhejiang University, Hangzhou, Zhejiang 310016, P.R. China
}

Received February 18, 2019; Accepted July 10, 2019

DOI: $10.3892 /$ ol.2019.10732

\begin{abstract}
Genetic alterations are vital in the progression of thyroid carcinoma. Ryanodine receptor 2 (RyR2) is reported to serve an important role in several types of human carcinoma. However, the expression and effect of RyR2 in thyroid carcinoma remain unknown. Therefore, the present study analyzed the status of RyR 2 in thyroid carcinoma using bioinformatics tools. The mRNA profiles of thyroid carcinoma were downloaded from The Cancer Genome Atlas. RyR2 was distinguished as a differentially expressed gene that has not been reported in thyroid carcinoma. Further analysis indicated that there was selective downregulation of RyR2 expression in thyroid carcinoma tissues compared with that in normal thyroid tissues. Survival analysis showed that RyR2 expression was associated with poorer disease-free survival (DFS) for all patients with thyroid carcinoma. Univariate analysis revealed that a low expression of RyR2 was significantly associated with lymphatic metastasis, extracapsular extension, and the Tumor-Node-Metastasis stage. Cox analysis demonstrated that RyR2 was an independent prognostic factor in thyroid carcinoma for DFS. The biological processes and signaling pathways of RyR2 were reviewed with Gene Set Enrichment Analysis. In conclusion, the present study has revealed that RyR2 is downregulated in thyroid carcinoma, and that low expression of RyR2 is associated with poor prognosis in patients with thyroid carcinoma. RyR2 may therefore serve as a promising tumor suppressor gene in thyroid carcinoma.
\end{abstract}

\section{Introduction}

Thyroid carcinoma is the most common malignancy of the endocrine system, and its incidence rate has been increasing worldwide over the past 10 years. The global incidence rate is

Correspondence to: Professor Li Gao, Department of Head and Neck Surgery, Sir Run Run Shaw Hospital, School of Medicine, Zhejiang University, 3 East Qingchun Road, Hangzhou, Zhejiang 310016, P.R. China

E-mail:srrs_gl@sina.com

Key words: thyroid carcinoma, ryanodine receptor 2, prognosis, The Cancer Genome Atlas, bioinformatics analysis
10.2 cases per 100,000 in women and 3.1 cases per 100,000 in men (1-5). In the United States (6,7), thyroid carcinoma is now the fifth most common cancer in women and will replace colon cancer as the fourth leading cancer by 2030 . In Korea (8), thyroid carcinoma has rapidly increased by $24.2 \%$ per year in women between 2000 and 2010, and the incidence rate of 18.1 cases per 100,000 is the highest in the world, while in China (9), thyroid carcinoma is the third most common cancer in women, and has become a common disease harmful to human health. This increase may partly be explained by environmental pollution, ionizing radiation, sex hormone levels and occupational stress (10-14). Concurrent with the developing economy, there has been an increase in the concentration of pollutants in the environment. This includes air, water, soil and noise pollution as well as an increase in contaminant garbage waste (15-18). It is well-established that ionizing radiation is a risk factor for thyroid carcinoma (19). Major sources of ionizing radiation includes radioactive material from nuclear waste and medical examinations (for example, computerized tomography and $\mathrm{x}$-rays), and there is an increased probability of exposure to ionizing radiation. Additionally, as society and societal roles have developed, there are now more women in the workforce which may result in additional work-related stress and thus changes to hormone levels (20).

Thyroid carcinoma is generally considered a neoplastic disease, and most patients usually have a favorable prognosis with a 10 -year survival rate $>90$ percent when treated by conventional surgery and adjuvant radioiodine. However, thyroid carcinoma cells can metastasize in the early stages of the disease to lymph nodes through the blood and lymphatic systems, which may lead to recurrence and distant metastasis in $10-20 \%$ of patients $(21,22)$. Some cases have a poor response to conventional treatment resulting in a low 10 -year survival rate of $20-30 \%(23,24)$. Therefore, a better understanding of thyroid carcinoma progression and prognosis prediction is urgently required to improve the outcome of patients with thyroid carcinoma.

Ryanodine receptors (RyRs) are the largest of the ion channels. Ryanodine receptor type 2 (RyR2), a member of the RyR family, is a homotetrameric protein complex that regulates $\mathrm{Ca}^{2+}$ release from sarcoplasmic reticulum into the cytosol (25). Gene transcription, vesicle secretion, and cell proliferation are controlled by intracellular $\mathrm{Ca}^{2+}$ levels (26), and imbalances in $\mathrm{Ca}^{2+}$ homeostasis and abnormal increases in cytosolic $\mathrm{Ca}^{2+}$ 
induce apoptosis (27). There is increasing evidence to suggest that intracellular $\mathrm{Ca}^{2+}$ homeostasis is altered in cancer cells, and that these alterations are involved in tumor angiogenesis, genetic mutations, and cellular migration (28). Previous studies have confirmed that RyR2 is associated with several types of cancers, including melanoma (29), breast cancer (30), lymphoma (31), and prostate cancer (32). However, few studies to date have assessed the expression and biological function of RyR2 in thyroid carcinoma.

The present study analyzed the relationship between RyR2 mRNA expression and thyroid carcinoma. A bioinformatics analyses revealed that RyR2 was downregulated in thyroid carcinoma tissues, and low expression levels of RyR2 were closely associated with poor prognosis in thyroid carcinoma patients.

\section{Materials and methods}

Data source. Gene expression data and clinical information on patients with thyroid carcinoma were obtained from the Genomic Data Commons Data Portal within The Cancer Genomes Atlas (TCGA) (https://portal.gdc.cancer.gov/) using TCGAbiolinks R/Bioconductor package (in October 2018). First, the RNA-seq data files were merged into a matrix file using the merge script of the Perl language (http://www.perl.org/). Then, the gene name was converted from the Ensembl ID to the matrix of the gene symbol through the Ensembl database version 84 (asia.ensembl.org/index. html). These downloaded data included a total of 506 thyroid carcinoma samples and 57 normal thyroid samples. The data of RyR2 were extracted and analyzed. The differentially expressed genes (DEGs) analysis with RNAseq data was performed using $\mathrm{R}$ (version 3.6.0) (33) package edgeR version 3.27.6 (r-project. org/). False discovery rate $<0.05, \log _{2}$ counts per million $>1$ and $\mid \log _{2}$ fold changel $>2$ were set as inclusion criteria for the DEGs selection. The gene expression level based on microarray data was calculated using $\mathrm{R}$ package limma (version 3.40.2; bioconductor.org/packages/release/bioc/html/limma.html) with robust multiarray average (RMA) correction.

Gene information acquisition and clinicopathological features. Gene information for normal thyroid and thyroid carcinoma expressing RyR2 were obtained from the downloaded data. Cases missing relevant clinicopathological parameters (including age, sex, race, lymphatic metastasis, extracapsular extension and Tumor-Node-Metastasis (TNM) stage (34) and prognostic follow-up data were eliminated. A total of 555 samples (498 tumors and 57 normal samples) were analyzed in the present study. The median expression level of 134 for RyR2 in thyroid carcinoma was used as the cutoff. Low RyR 2 expression in each of the 249 patients was defined as a value below the 50th percentile. High RyR2 expression in each of the 249 patients was defined as a value above the 50th percentile. Significance was first evaluated using the Kruskal-Wallis test. A Mann-Whitney test was used to evaluate the differences between any two groups, followed Bonferroni's correction with a cut-off of $\mathrm{P}=0.0167$ was used to correct for multiple comparisons. The $\chi^{2}$ and Fisher exact tests were used to evaluate the association between clinicopathological characteristics and RyR2 expression.

Prognostic analysis. Using the median value of RyR2 expression as mentioned above, patients with thyroid carcinoma were classified into RyR2 high group and RyR2 low group. Kaplan-Meier analysis was used to generate disease-free survival (DFS) curves, and log-rank tests were performed to assess DFS differences between RyR2 high and low expression groups. Univariate and multivariate analyses with Cox proportional hazards regression for DFS were performed on individual clinical risk factors with and without the RyR2 expression. Hazard ratios and $95 \%$ confidence intervals were determined.

Functional enrichment analysis. Enrolled patients were divided into high and low expression groups based on their RyR2 expression as described above. In the present study, the c2.cp.kegg.v6.0.symbols.gmt data set was downloaded from the Molecular Signatures Database from the Gene Set Enrichment Analysis (GSEA) website (version 3.0; software. broadinstitute.org/gsea/index.jsp). Then, enrichment analysis was performed by the default weighted enrichment method, and the number of random combinations was set at 1,000.

Statistical analysis. Statistical analyses were performed using SPSS v21.0 software (IBM, Corp.). The edger function was used to analyze mRNA profiles between normal and thyroid carcinoma tissues. The different expression of RyR2 mRNA in normal, high and low RyR2 expression groups were evaluated using the Kruskal-Wallis test, following which the Mann-Whitney test was used to evaluate the differences between any two groups, and the Bonferroni's correction was performed to account for multiple corrections. $\mathrm{X}^{2}$ and Fisher exact tests were used to evaluate the association between clinicopathological characteristics and RyR 2 expression. In addition, the association between RyR 2 and the prognosis of patients with thyroid carcinoma was evaluated with the Kaplan-Meier method and log-rank test. Univariate and multivariate analyses were performed using the Cox regression model. $\mathrm{P}<0.05$ were considered to indicate a statistically significant difference.

\section{Results}

RyR2 is significantly downregulated in thyroid carcinoma. The expression of RyR2 mRNA in normal and thyroid carcinoma tissue was investigated using gene expression profiles downloaded from TCGA database. The results from TCGA cohort indicated that RyR2 expression was significantly lower in both high RyR2 expressing and low RyR2 expressing thyroid carcinoma groups compared with the normal thyroid group $(\mathrm{P}<0.01)$ (Fig. 1).

Relationship between RyR2 expression and clinicopathological characteristics. To explore whether RyR2 expression is associated with clinicopathological features of thyroid carcinoma, the clinicopathological characteristics of 498 patients with thyroid carcinoma from TCGA database were analyzed. According to the median value of RyR2 expression, patients were divided into either high RyR2 expression $(n=249)$ or low RyR2 expression ( $n=249)$ groups. In the present study, RyR2 expression was significantly associated with lymph node metastasis $(\mathrm{P}<0.001)$, extracapsular extension $(\mathrm{P}<0.001)$, and TNM stage $(27)(\mathrm{P}<0.001)$ (Table I). However, there was no association with other characteristics including age, sex, or ethnic background ( $\mathrm{P}>0.05)$. 
A

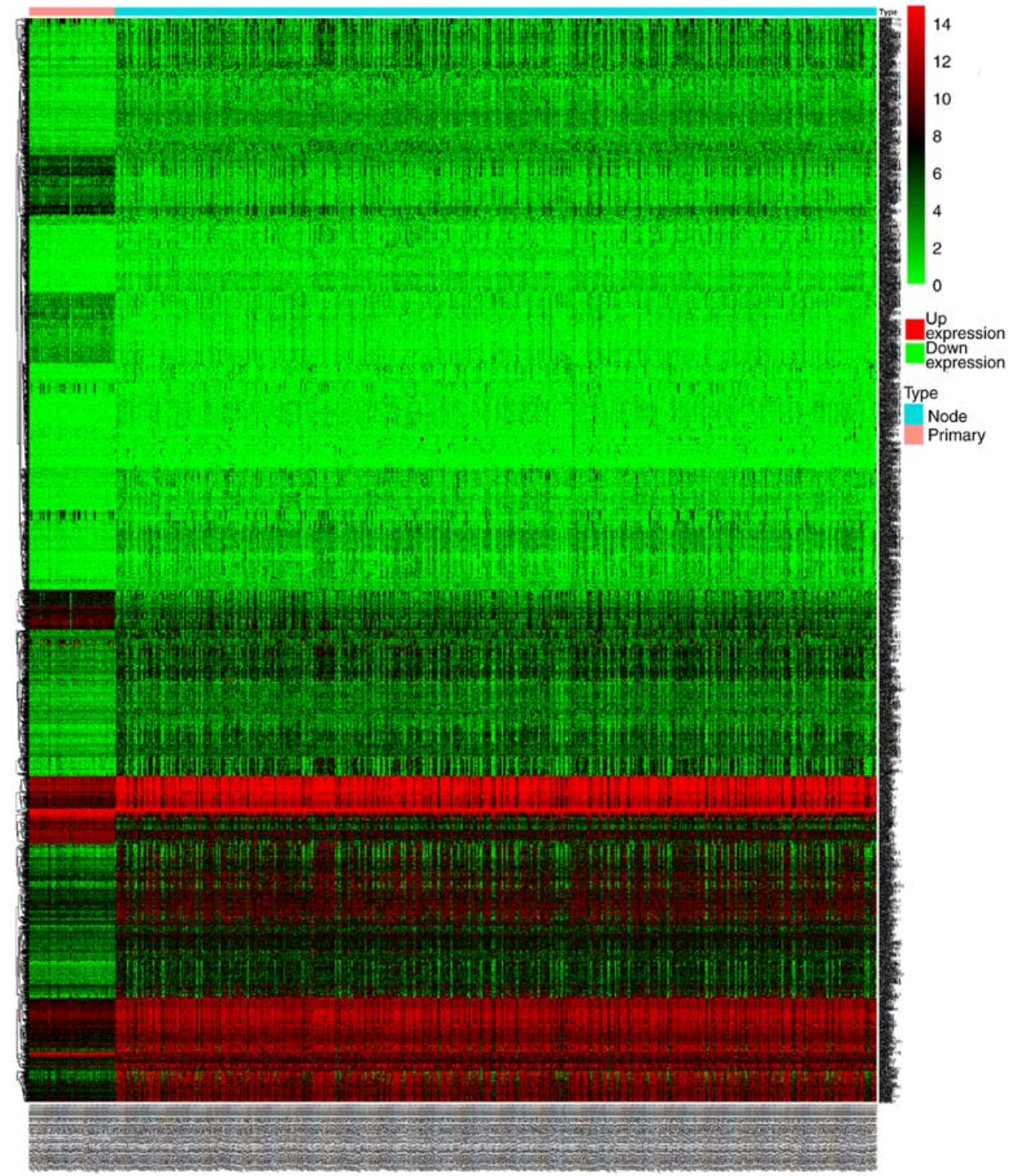

B

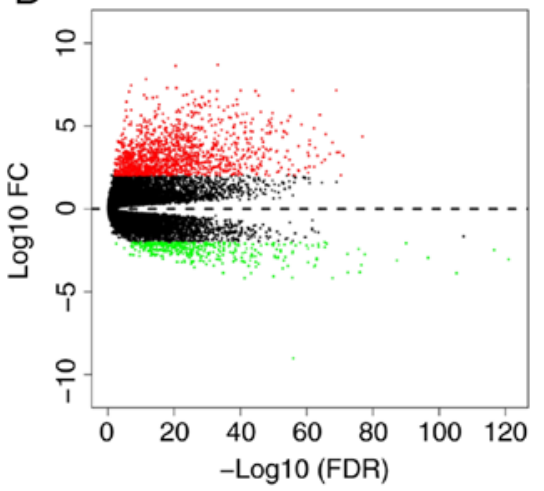

C

Up expression Down expression

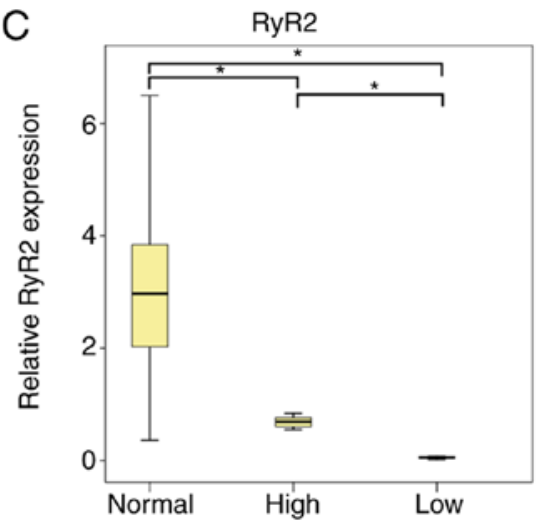

Figure 1. Expression of RyR2 in thyroid carcinoma from the TCGA database. (A) heatmap and (B) volcano plot of mRNA expression in thyroid cancer. (C) RyR2 mRNA expression levels. Thyroid cancer with high, low or normal RyR2 expression. " $\mathrm{P}<0.01$.

Association between RyR2 expression and prognosis of thyroid carcinoma. The prognostic role of RyR2 in thyroid carcinoma was investigated using Kaplan-Meier and Cox regression analyses. The results indicated that patients with low RyR2 mRNA levels had a shorter disease-free survival (DFS) compared with that in patients with high RyR2 mRNA levels $(\mathrm{P}=0.00382$; Fig. 2). Furthermore, univariate analysis showed that lymphatic metastasis, extracapsular extension, 
Table I. Relationship between the RyR2 expression and clinicopathological characteristics in patients with thyroid carcinoma.

\begin{tabular}{|c|c|c|c|c|}
\hline \multirow[b]{2}{*}{ Clinicopathological characteristics } & \multicolumn{2}{|c|}{ RyR2 expression } & \multirow[b]{2}{*}{$\chi^{2}$ value } & \multirow[b]{2}{*}{ P-value } \\
\hline & Low, $n=249$ & High, $n=249$ & & \\
\hline Age, years & & & 1.168 & 0.28 \\
\hline$<45$ & 106 & 118 & & \\
\hline$\geq 45$ & 143 & 131 & & \\
\hline Sex & & & 0.01 & 0.919 \\
\hline Male & 67 & 66 & & \\
\hline Female & 182 & 183 & & \\
\hline Race & & & 2.781 & 0.249 \\
\hline White & 202 & 200 & & \\
\hline Black or African American & 20 & 13 & & \\
\hline Asian & 27 & 36 & & \\
\hline Lymphatic metastasis & & & 11.600 & $\mathrm{P}<0.001$ \\
\hline No & 107 & 145 & & \\
\hline Yes & 142 & 104 & & \\
\hline Extracapsular extension & & & 10.364 & $\mathrm{P}<0.001$ \\
\hline No & 135 & 170 & & \\
\hline Yes & 114 & 79 & & \\
\hline TNM stage & & & 11.036 & $\mathrm{P}<0.001$ \\
\hline I and II & 148 & 183 & & \\
\hline III and IV & 101 & 66 & & \\
\hline
\end{tabular}

${ }^{\mathrm{a}}$ Chi-square test.

TNM stage, and RyR2 expression were associated with DFS $(\mathrm{P}<0.05)$. Multivariate analysis demonstrated that RyR2 expression was an independent prognostic factor in thyroid carcinoma for DFS (Table II). Moreover, RyR2 expression was negatively associated with lymphatic metastasis, extracapsular extension, and TNM stage (Table I). The results of Tables I and II suggest that there is an association between RyR2 and the prognosis of thyroid carcinoma patients.

Function analysis of RyR2. Thyroid carcinoma patients were divided into high and low expression groups according to their RyR2 expression. The median expression level of RyR 2 was used as the cutoff. To clarify the function of RyR2 in thyroid carcinoma, Gene Set Enrichment Analysis (GSEA) was used for enrichment. RyR2 is associated with ' $\beta$-alanine metabolism' (Fig. 3A; $\mathrm{P}<0.001$ ), 'ascorbate and aldarate metabolism' (Fig. 3B; $\mathrm{P}=0.004)$, 'fatty acid metabolism' (Fig. 3C; $\mathrm{P}=0.002$ ), 'primary bile acid biosynthesis' (Fig. 3D; $\mathrm{P}=0.008)$, 'glycine serine and threonine metabolism' (Fig. 3E; $\mathrm{P}=0.008$ ), 'lysine degradation' (Fig. 3F; $\mathrm{P}=0.008$ ), 'calcium signaling' (Fig. 3G; $\mathrm{P}=0.006$ ), and 'TGF- $\beta$ signaling' (Fig. $3 \mathrm{H} ; \mathrm{P}=0.008$ ).

\section{Discussion}

Thyroid carcinoma is one of the most common malignant tumors in China. It is generally considered to be a neoplastic disease with a good prognosis. However, thyroid carcinoma has a high recurrence rate after surgery, and there are individual

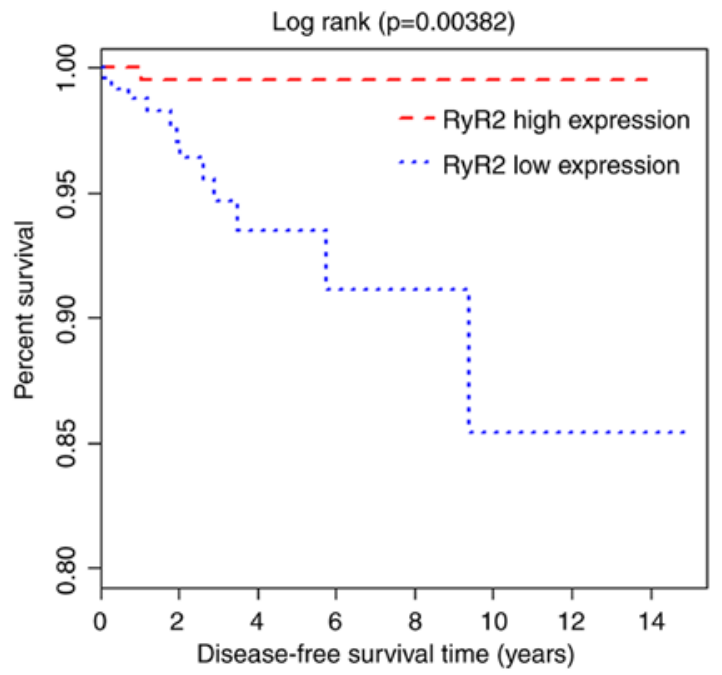

Figure 2. Association between RyR2 expression and disease-free survival in patients with thyroid carcinoma.

differences in patients $(35,36)$. Thus, novel factors that could more effectively predict the prognosis of thyroid carcinoma require identification. In the present study, the expression of RyR2 in thyroid carcinoma and its function in predicting the prognosis of patients with thyroid carcinoma was investigated. Low RyR2 expression was associated with poor prognosis of patients with thyroid carcinoma. 
Table II. Cox regression analysis of RyR2 expression and clinicopathological characteristics for disease-free survival in patients with thyroid carcinoma.

\begin{tabular}{|c|c|c|c|c|}
\hline \multirow[b]{2}{*}{ Clinicopathological characteristics } & \multicolumn{2}{|c|}{ Univariate analysis } & \multicolumn{2}{|c|}{ Multivariate analysis } \\
\hline & $\mathrm{HR}(95 \% \mathrm{CI})$ & P-value & $\mathrm{HR}(95 \% \mathrm{CI})$ & P-value \\
\hline \multicolumn{5}{|l|}{ Age, years } \\
\hline$<45$ vs. $\geq 45$ & $1.183(0.437-3.325)$ & 0.619 & $1.351(0.572-2.968)$ & 0.714 \\
\hline \multicolumn{5}{|l|}{ Sex } \\
\hline Male vs. female & $1.057(0.266-2.639)$ & 0.894 & $1.315(0.402-3.347)$ & 0.629 \\
\hline \multicolumn{5}{|l|}{ Race } \\
\hline White vs. Black or African American vs. Asian & $1.258(0.714-1.893)$ & 0.376 & $1.421(0.503-4.624)$ & 0.481 \\
\hline \multicolumn{5}{|l|}{ Lymphatic metastasis } \\
\hline No vs. Yes & $2.417(1.611-3.690)$ & $0.027^{\mathrm{a}}$ & $2.762(1.783-4.176)$ & $0.034^{\mathrm{a}}$ \\
\hline \multicolumn{5}{|l|}{ Extracapsular extension } \\
\hline No vs. Yes & $1.682(1.012-2.656)$ & $0.031^{\mathrm{a}}$ & $1.538(1.124-2.537)$ & $0.042^{\mathrm{a}}$ \\
\hline \multicolumn{5}{|l|}{ TNM stage } \\
\hline I and II vs. III and IV & $3.531(2.219-5.647)$ & $0.015^{\mathrm{a}}$ & $3.726(2.401-5.893)$ & $0.019^{\mathrm{a}}$ \\
\hline \multicolumn{5}{|l|}{ RyR2 expression } \\
\hline Low vs. high ${ }^{\mathrm{a}}$ & $5.293(3.505-8.044)$ & $0.007^{\mathrm{a}}$ & $5.341(3.547-8.128)$ & $0.012^{\mathrm{a}}$ \\
\hline
\end{tabular}

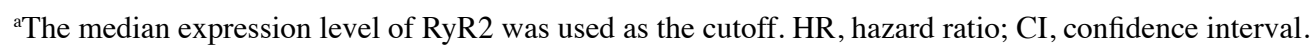

Intracellular calcium ions $\left(\mathrm{Ca}^{2+}\right)$ have important roles in fundamental cellular physiology (37). Disruption of intracellular $\mathrm{Ca}^{2+}$ homeostasis contributes to tumor cell proliferation and reduced apoptosis $(38,39)$. Additionally, accumulating evidence has demonstrated that severe and persistent endoplasmic reticulum (ER) stress or suppression of ER stress results in tumor cell death (40). RyR is an ER cation channel that releases ER $\mathrm{Ca}^{2+}$ into the cytosol (41). RyRs form large protein complexes comprising calmodulin, protein kinases, and protein phosphatases. In previous research, it has been reported that RyR can upregulate the activity of mitogenic pathways, including RAS/mitogen-associated protein kinase (42), and promote T cell activation (43). Furthermore, Abdul et al (44) found that there was a strong negative association between RyR levels and breast tumor grade. However, the association between the expression of RyR2 and clinicopathological characteristics in thyroid carcinoma remained unclear.

According to the 8th AJCC staging system (34), minimal/minor extrathyroidal extension (mETE) is no longer regarded as a criterion of advanced stage cancer. Our hypothesis is that this is currently published in different versions of mETE in 8th AJCC staging system for the following reasons: First, capsula glanduloe thyreoideae is imperfect, and normal thyroid tissue may contain adipose or skeletal muscle tissue. Thus, mETE cannot be defined clearly. Secondly, a number of studies have found that mETE is not an independent prognostic risk factor in patients with thyroid carcinoma. Following the publishing of the 8th AJCC staging system, it also caused widespread controversy. Many researchers have presented different views against the new staging system, as they consider that mETE can increase the risk of thyroid carcinoma recurrence (45). In the 8th AJCC staging system, any lymph node involvement in either the central or lateral neck defines a patient as stage group II (in the absence of gross extrathyroidal extension or distant metastases) in patients aged 55 years or older. While in a number of studies, the presence of lymph node metastasis was associated with a statistically significant decrease in survival rate $(46,47)$. Furthermore, lateral lymph node metastasis is considered to be an independent prognostic risk factor in patients with thyroid carcinoma $(48,49)$. In the present study, RyR2 mRNA was downregulated in thyroid carcinoma, and low expression of RyR2 was associated with lymph node metastasis, extracapsular extension, and high TNM staging, which suggested poor prognosis of patients with thyroid carcinoma. Moreover, patients with low RyR2 expression had a poorer DFS compared with that in patients with high RyR2 expression. Univariate and multivariate Cox regression analyses showed that RyR2 was an independent prognostic factor for DFS in thyroid carcinoma. Taken together, these results indicated that RyR2 is involved in the protection of thyroid carcinoma. In order to reveal the biological processes and signaling pathways of RyR2 in thyroid carcinoma, GSEA was used, which revealed that RyR2 was enriched in ' $\beta$-alanine metabolism', 'ascorbate and aldarate metabolism', 'fatty acid metabolism', 'primary bile acid biosynthesis', 'glycine serine and threonine metabolism', and 'lysine degradation', these signaling pathways were closely associated with 'cellular metabolism' and 'cell activity'. RyR2 was also enriched in 'calcium signaling pathway' and 'TGF- $\beta$ signaling pathway', these two signaling pathway themselves were closely associated with cell signaling and tumor regression. Further investigation is required to verify these biological processes and signaling pathways modulated by RyR 2 in thyroid carcinoma in future studies. 

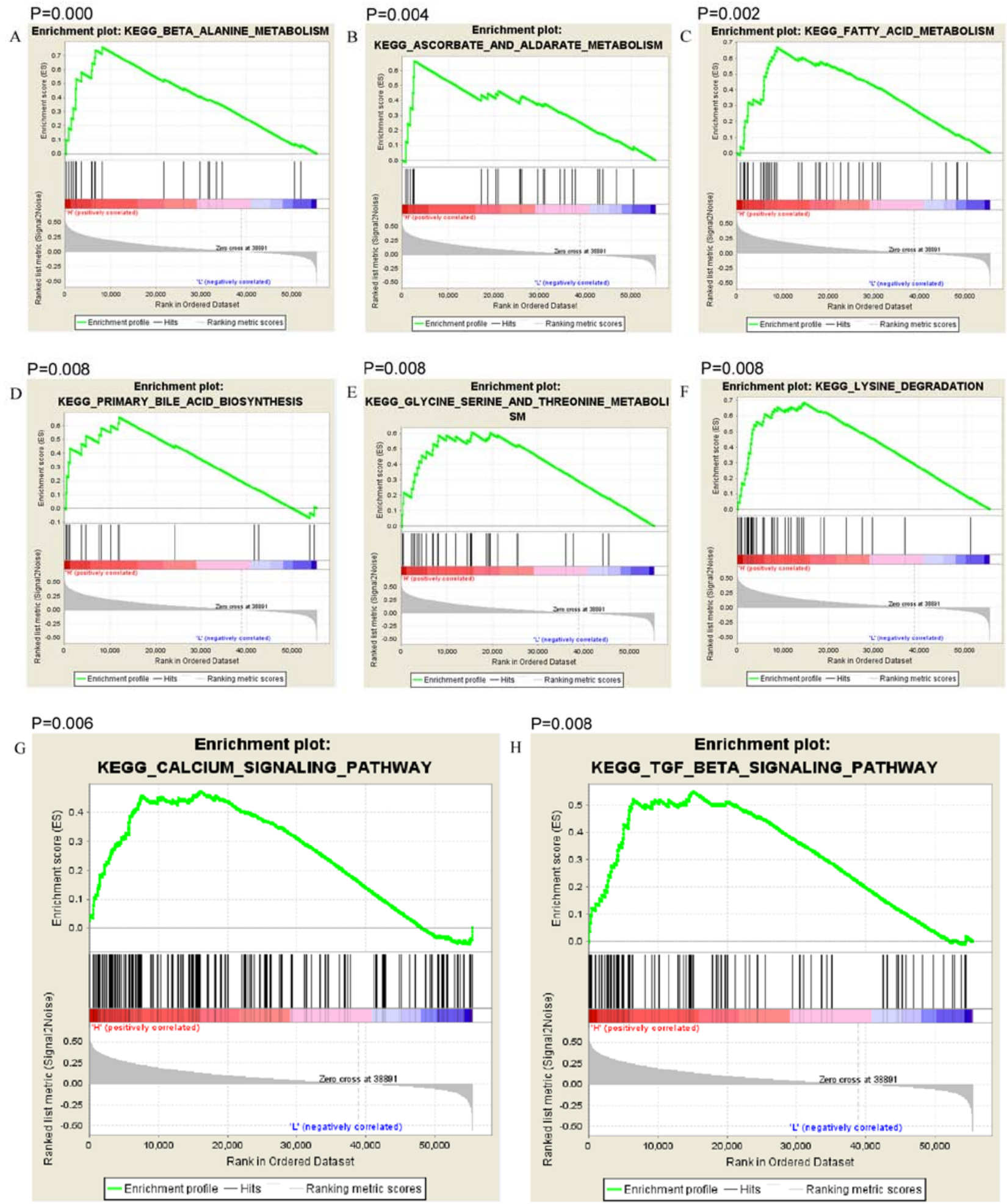

Figure 3. Biological process associated with RyR2 expression. (A) $\beta$-alanine metabolism. (B) Ascorbate and aldarate metabolism. (C) Fatty acid metabolism. (D) Primary bile acid biosynthesis. (E) Glycine serine and threonine metabolism. (F) Lysine degradation. (G) Calcium signaling. (H) TGF- $\beta$ signaling.

Taken together, the present comprehensive analysis demonstrated the expression and prognostic value of RyR2 in thyroid carcinoma. We found that low expression of RyR2 is associated with the poor prognosis of patients with thyroid carcinoma. Therefore, RyR 2 might be a potential tumor suppressor gene for thyroid carcinoma. The exact mechanisms of RyR2 in thyroid carcinoma remain unclear, and thus further studies investigating RyR 2 and thyroid carcinoma pathogenesis are required. A total of
555 samples (498 tumors and 57 normal samples) were analyzed in our study. A larger cohort of tumor and normal samples is required in future studies to improve the statistical power. In the present study, the expression value of RyR2 in 498 patients with thyroid carcinoma were presented as abnormal distribution, but as the median level of RyR2 was used as the cutoff to divide patients into high and low RyR 2 expression groups, this method may be inaccurate. Therefore, more accurate statistical 
methods are required in future studies. In addition, the expression of RyR2 and its effects should be determined separately for the different subtypes of thyroid carcinoma, including papillary thyroid carcinoma (PTC), follicular thyroid carcinoma (FTC), medullary thyroid carcinoma (MTC) and anaplastic thyroid carcinoma (ATC). PTC and FTC generally present with indolent behavior and has a favorable prognosis. MTC is an aggressive thyroid carcinoma, deriving from parafollicular cells. ATC is the most aggressive type of thyroid carcinoma and responsible for more than half of all thyroid cancer deaths. Different variants of thyroid carcinoma have distinct biological behaviors and prognosis, thus the expression of RyR2 may differ between different variants of thyroid carcinoma, and these will also require further investigation.

\section{Acknowledgements}

Not applicable.

\section{Funding}

The present study was funded by The Center for Diagnosis and Treatment of Thyroid Diseases in Sir Run Run Shaw Hospital, School of Medicine, Zhejiang University (Zheijiang, China).

\section{Availability of data and materials}

All the data collected and analyzed in the study are available from the corresponding author on reasonable request.

\section{Authors' contributions}

LG and NX designed the study. NX, DZ, JC and GH performed the data collection and analysis. All authors participated in the writing of the manuscript. All the authors have read and approved the final version of this manuscript.

\section{Ethics approval and consent to participate}

Not applicable.

\section{Patient consent for publication}

Not applicable.

\section{Competing interests}

The authors declare that they have no competing interests.

\section{References}

1. La Vecchia C, Malvezzi M, Bosetti C, Garavello W, Bertuccio P, Levi F and Negri E: Thyroid cancer mortality and incidence: A global overview. Int J Cancer 136: 2187-2195, 2015.

2. Rahib L, Smith BD, Aizenberg R, Rosenzweig AB Fleshman JM and Matrisian LM: Projecting cancer incidence and deaths to 2030: The unexpected burden of thyroid, liver, and pancreas cancers in the United States. Cancer Res 74 2913-2921, 2014.

3. Pellegriti G, Frasca F, Regalbuto C, Squatrito S and Vigneri R: Worldwide increasing incidence of thyroid cancer: Update on epidemiology and risk factors. J Cancer Epidemiol 2013: 965212, 2013.
4. Siegel R, Ward E, Brawley O and Jemal A: Cancer statistics, 2011: The impact of eliminating socioeconomic and racial disparities on premature cancer deaths. CA Cancer J Clin 61: 212-236, 2011.

5. Bray F, Ferlay J, Soerjomataram I, Siegel RL, Torre LA and Jemal A: Global cancer statistics 2018: GLOBOCAN estimates of incidence and mortality worldwide for 36 cancers in 185 countries. CA Cancer J Clin 68: 394-424, 2018.

6. Weir HK, Thompson TD, Soman A, Møller B and Leadbetter S: The past, present, and future of cancer incidence in the United States: 1975 through 2020. Cancer 121: 1827-1837, 2015.

7. Siegel RL, Miller KD and Jemal A: Cancer statistics, 2016. CA Cancer J Clin 66: 7-30, 2016.

8. Jung KW, Won YJ, Kong HJ, Oh CM, Seo HG and Lee JS: Cancer statistics in Korea: Incidence, mortality, survival and prevalence in 2010. Cancer Res Treat 45: 1-14, 2013.

9. Cabanillas ME, McFadden DG and Durante C: Thyroid cancer. Lancet 388: 2783-2795, 2016.

10. McLeod DS, Cooper DS, Ladenson PW, Ain KB, Brierley JD, Fein HG, Haugen BR, Jonklaas J, Magner J, Ross DS, et al: Prognosis of differentiated thyroid cancer in relation to serum thyrotropin and thyroglobulin antibody status at time of diagnosis. Thyroid 24: 35-42, 2014.

11. Han MA and Kim JH: Diagnostic X-Ray exposure and thyroid cancer risk: Systematic review and meta-analysis. Thyroid 28: 220-228, 2018.

12. Hong SH, Myung SK and Kim HS; Korean Meta-Analysis (KORMA) Study Group: Alcohol intake and risk of thyroid cancer: A Meta-analysis of observational studies. Cancer Res Treat 49: 534-547, 2017.

13. Marotta V, Russo G, Gambardella C, Grasso M, La Sala D Chiofalo MG, D'Anna R, Puzziello A, Docimo G, Masone S, et al: Human exposure to bisphenol AF and diethylhexylphthalate increases susceptibility to develop differentiated thyroid cancer in patients with thyroid nodules. Chemosphere 218: 885-894, 2019.

14. Kurata A: Differentiated thyroid cancer: Why does it affect predominantly women during the reproductive period and have higher incidence of mutual association with breast cancer. Med Hypotheses 122: 5-7, 2019.

15. Yan Z, Pan J, Gao F, An Z, Liu H, Huang Y and Wang X: Seawater quality criteria derivation and ecological risk assessment for oil pollution in China. Mar Pollut Bull 142: 25-30, 2019.

16. Bai L, Wang J, Ma X and Lu H: Air pollution forecasts: An overview. Int J Environ Res Public Health 15: pii: E780, 2018.

17. Dehghani MH, Mosavi MF, Ale-Sheikh AA, Heidarinejad Z and Yousefi M: Experimental data of designing an optimal system for storage, collection and transfer of household waste in the GIS environment: A case study of Tehran, district 22, Iran. Data Brief 19: 1605-1613, 2018.

18. Chae Y and An YJ: Current research trends on plastic pollution and ecological impacts on the soil ecosystem: A review. Environ Pollut 240: 387-395, 2018.

19. Albi E, Cataldi S, Lazzarini A, Codini M, Beccari T, Ambesi-Impiombato FS and Curcio F: Radiation and thyroid cancer. Int J Mol Sci 18: pii: E911, 2017.

20. Salem R, Haibe Y, Dagher C, Salem C, Shamseddine A, Bitar N, Makdessi J, Khatib S, Boussen H, Benna F, et al: Female oncologists in the Middle East and North Africa: Progress towards gender equality. ESMO Open 4: e000487, 2019.

21. Siraj AK, Pratheeshkumar P, Parvathareddy SK, Bu R, Masoodi T, Iqbal K, Al-Rasheed M, Al-Dayel F, Al-Sobhi SS, Alzahrani AS, et al: Prognostic significance of DNMT3A alterations in Middle Eastern papillary thyroid carcinoma. Eur J Cancer 117: 133-144, 2019.

22. Markovina S, Grigsby PW, Schwarz JK, DeWees T, Moley JF, Siegel BA and Perkins SM: Treatment approach, surveillance, and outcome of well-differentiated thyroid cancer in childhood and adolescence. Thyroid 24: 1121-1126, 2014.

23. Amaral L, Bufalo NE, Peres KC, Barreto IS, Campos A and Ward LS: ID proteins may reduce aggressiveness of thyroid tumors. Endocr Pathol 30: 24-30, 2019.

24. Zanotti-Fregonara P, Rubello D and Hindié E: Bone metastases of differentiated thyroid cancer: The importance of early diagnosis and 131I therapy on prognosis. J Nucl Med 49: 1902-1903, 2008.

25. Ding Z, Yuan J, Liang Y, Wu J, Gong H, Ye Y, Jiang G, Yin P, Li Y, Zhang G, et al: Ryanodine receptor type 2 plays a role in the development of cardiac fibrosis under mechanical stretch through TGF $\beta$-1. Int Heart J 58: 957-961, 2017.

26. Görlach A, Klappa P and Kietzmann T: The endoplasmic reticulum: Folding, calcium homeostasis, signaling, and redox control. Antioxid Redox Signal 8: 1391-1418, 2006. 
27. Shin DH, Leem DG, Shin JS, Kim JI, Kim KT, Choi SY, Lee MH, Choi JH and Lee KT: Compound K induced apoptosis via endoplasmic reticulum $\mathrm{Ca}^{2+}$ release through ryanodine receptor in human lung cancer cells. J Ginseng Res 42: 165-174, 2018.

28. Cui C, Merritt R, Fu L and Pan Z: Targeting calcium signaling in cancer therapy. Acta Pharm Sin B 7: 3-17, 2017.

29. Carpi S, Polini B, Poli G, Alcantara Barata G, Fogli S, Romanini A, Tuccinardi T, Guella G, Frontini FP, Nieri P and Di Giuseppe G: Anticancer activity of Euplotin C, isolated from the marine ciliate Euplotes crassus, against human melanoma cells. Mar Drugs 16: pii: E166, 2018

30. Lu H, Chen I, Shimoda LA, Park Y, Zhang C, Tran L, Zhang H and Semenza GL: Chemotherapy-Induced $\mathrm{Ca}^{2+}$ release stimulates breast cancer stem cell enrichment. Cell Rep 18: 1946-1957, 2017.

31. McCarthy TV, Datar S and Mackrill JJ: Activation of ryanodine receptor/Ca2+ release channels downregulates CD38 in the Namalwa B lymphoma. FEBS Lett 554: 133-137, 2003.

32. Mariot P, Prevarskaya N, Roudbaraki MM, Le Bourhis X, Van Coppenolle F, Vanoverberghe K and Skryma R: Evidence of functional ryanodine receptor involved in apoptosis of prostate cancer (LNCaP) cells. Prostate 43: 205-214, 2000.

33. R Core Team. R: A language and environment for statistical computing. R Foundation for Statistical Computing, Vienna, Austria. 2012 ISBN 3-900051-07-0, URL http://www.R-project. org/.

34. Amin MB, Greene FL, Edge SB, Compton CC, Gershenwald JE, Brookland RK, Meyer L, Gress DM, Byrd DR and Winchester DP: The Eighth edition AJCC cancer staging manual: Continuing to build a bridge from a population-based to a more 'personalized' approach to cancer staging. CA Cancer J Clin 67: 93-99, 2017.

35. George N, Agarwal A, Kumari N, Agarwal S, Krisnani N and Gupta SK: Molecular profiling of follicular variant of papillary thyroid cancer reveals Low-risk noninvasive follicular thyroid neoplasm with papillary-like nuclear features: A paradigm shift to reduce aggressive treatment of indolent tumors. Indian J Endocrinol Metab 22: 339-346, 2018.

36. Yang L, Yuan Y, Sun T, Li H and Wang N: Population-based cancer incidence analysis in Beijing, 2008-2012. Chin J Cancer Res 27: 13-21, 2015.

37. Berridge MJ, Lipp $P$ and Bootman MD: The versatility and universality of calcium signalling. Nat Rev Mol Cell Biol 1: 11-21, 2000.

38. Kondratskyi A, Yassine M, Kondratska K, Skryma R, Slomianny C and Prevarskaya N: Calcium-permeable ion channels in control of autophagy and cancer. Front Physiol 4: $272,2013$.

39. Zhu H, Zhang H, Jin F, Fang M, Huang M, Yang CS, Chen T, Fu L and Pan Z: Elevated Orail expression mediates tumor-promoting intracellular $\mathrm{Ca} 2+$ oscillations in human esophageal squamous cell carcinoma. Oncotarget 5: 3455-3471, 2014.
40. Dolai S, Pal S, Yadav RK and Adak S: Endoplasmic reticulum stress-induced apoptosis in Leishmania through Ca2+-dependent and caspase-independent mechanism. J Biol Chem 286: 13638-13646, 2011.

41. Santulli G and Marks AR: Essential roles of intracellular calcium release channels in muscle, brain, metabolism, and aging. Curr Mol Pharmaco 8: 206-222, 2015.

42. Xu C, Luo J, He L, Montell C and Perrimon N: Oxidative stress induces stem cell proliferation via TRPA1/RyR-mediated $\mathrm{Ca}^{2+}$ signaling in the Drosophila midgut. Elife 6: pii: e22441, 2017.

43. Wolf IM, Diercks BP, Gattkowski E, Czarniak F, Kempski J, Werner R, Schetelig D, Mittrücker HW, Schumacher V, von Osten $\mathrm{M}$, et al: Frontrunners of $\mathrm{T}$ cell activation: Initial, localized $\mathrm{Ca} 2+$ signals mediated by NAADP and the type 1 ryanodine receptor. Sci Signal 8: ra102, 2015.

44. Abdul M, Ramlal S and Hoosein N: Ryanodine receptor expression correlates with tumor grade in breast cancer. Pathol Oncol Res 14: 157-160, 2008.

45. Tran B, Roshan D, Abraham E, Wang L, Garibotto N, Wykes J, Campbell P and Ebrahimi A: An analysis of the American Joint Committee on Cancer 8th Edition T Staging system for papillary thyroid carcinoma. J Clin Endocrinol Metab 103: 2199-2206, 2018.

46. Wu MH, Shen WT, Gosnell J and Duh QY: Prognostic significance of extranodal extension of regional lymph node metastasis in papillary thyroid cancer. Head Neck 37: 1336-1343, 2015.

47. Kim HI, Kim TH, Choe JH, Kim JH, Kim JS, Oh YL, Hahn SY, Shin JH, Jang HW, Kim YN, et al: Restratification of survival prognosis of N1b papillary thyroid cancer by lateral lymph node ratio and largest lymph node size. Cancer Med 6: 2244-2251, 2017.

48. Kim HI, Kim K, Park SY, Choe JH, Kim JH, Kim JS, Oh YL, Hahn SY, Shin JH, Ahn HS, et al: Refining the eighth edition AJCC TNM classification and prognostic groups for papillary thyroid cancer with lateral nodal metastasis. Oral Oncol 78: 80-86, 2018.

49. Kim M, Jeon MJ, Oh HS, Park S, Song DE, Sung TY, Kim TY, Chung KW, Kim WB, Shong YK, et al: Prognostic Implication of N1b classification in the Eighth edition of the Tumor-Node-Metastasis staging system of differentiated thyroid cancer. Thyroid 28: 496-503, 2018.

This work is licensed under a Creative Commons Attribution-NonCommercial-NoDerivatives 4.0 International (CC BY-NC-ND 4.0) License. 